\title{
Paraneoplastic lipase and amylase production in a patient with small-cell lung cancer: case report
}

\author{
Andrea Casadei Gardini ${ }^{1 *}$, Marita Mariotti ${ }^{1}$, Alessandro Lucchesi ${ }^{1}$, Sara Pini ${ }^{1}$, Martina Valgiusti ${ }^{1}$, Sara Bravaccini ${ }^{2}$, \\ Angelo Del Monte ${ }^{1}$, Marco Angelo Burgio ${ }^{1}$, Giorgia Marisi ${ }^{2}$, Dino Amadori ${ }^{1}$ and Giovanni Luca Frassineti ${ }^{1}$
}

\begin{abstract}
Background: Small-cell lung cancer (SCLC) is known to express antigens of both the neural crest and epithelium, and to secrete polypeptide hormones and enzymes. Anecdotal reports correlate lung cancer with marked hyperamylasemia, and a review of the literature reveals only one case of metastatic SCLC linked to high paraneoplastic lipase production.

Case presentation: We present the case of a patient with metastatic SCLC who showed both lipase and pancreatic isoamylase elevation in the absence of acute pancreatitis.

Chemotherapy resulted in a rapid reduction in serum lipase and in pancreatic isoamylase which was correlated with the radiological response of the tumor to therapy. Lipase and pancreatic isoamylase expression in tumor cells from the lung biopsy was confirmed by immunohistochemical staining.

Conclusions: This is a very rare case of paraneoplastic syndrome linked to metastatic SCLC. The enzymes secreted could be used as markers of response to treatment until clonal selection mechanisms and intratumor heterogeneity induce changes in biochemical characteristics and consequently in tumor behavior.
\end{abstract}

Keywords: Small-cell lung cancer, Paraneoplastic syndrome, Serum lipase, Pancreatic amylase, Response marker

\section{Background}

Small-cell lung cancer (SCLC) is known to express antigens of both the neural crest and epithelium, and to secrete polypeptide hormones and enzymes. The most common paraneoplastic endocrine manifestations in SCLC are the syndrome of inappropriate antidiuretic hormone secretion (SIADH) and Cushing's syndrome [1, 2]. Anecdotal reports correlate lung cancer with marked hyperamylasemia, and a review of the literature shows only one case of metastatic SCLC linked to high paraneoplastic lipase production [3].

We present the case of a patient with metastatic SCLC who showed both lipase and pancreatic isoamylase elevation in the absence of acute pancreatitis. Chemotherapy induced a rapid decrease in serum lipase and in pancreatic isoamylase which was correlated with radiological confirmation of response of the tumor to therapy.

\footnotetext{
* Correspondence: andrea.casadei@irst.emr.it

${ }^{1}$ Department of Medical Oncology, Istituto Scientifico Romagnolo per lo

Studio e la Cura dei Tumori (IRST) IRCCS, Meldola, Italy

Full list of author information is available at the end of the article
}

\section{Case presentation}

A 54-year-old man presented with small cell lung cancer (SCLC) and metastases of the brain, liver, adrenal glands and mediastinal lymph nodes. Immunohistochemically, tumor cells were positive for CD56 and TTF1. The patient had a 30-year history of cigarette smoking and his past medical history was significant for arterial hypertension and diabetes. He only took medications for back pain and did not drink alcohol. Given his performance status, we considered first-line chemotherapy with cisplatin and etoposide. A blood test before the start of chemotherapy showed normal renal and liver functions but high serum lipase levels (1343 U/L, normal value 13-60 U/L). Further tests revealed elevated levels of neuron-specific enolase (NSE) $(173.9 \mu \mathrm{g} / \mathrm{L})$, carcinoembryonic antigen (220.7; normal value $<5 \mu \mathrm{g} / \mathrm{L}$ ) and serum amylase (379; normal value 1-100 U/L). Although progastrin-releasing peptide was recently identified as a biomarker of SCLC, we chose not to analyze it as it has 
not yet been introduced into clinical practice. Pancreatic isoamylase value was $339 \mathrm{U} / \mathrm{L}$ (normal value 17-115 U/L). Serum calcium and other electrolytes were normal. The patient was asymptomatic. Magnetic resonance imaging (MRI) of the abdomen performed to exclude pancreatic lesions and/or pancreatitis was negative (Fig. 1).

In the absence of clinical and radiological findings of pancreatitis, chemotherapy was begun with cisplatin and etoposide. After the first cycle of chemotherapy, serum lipase values decreased sharply to $592 \mathrm{U} / \mathrm{L}$ and NSE levels fell to $24 \mu \mathrm{g} / \mathrm{L}$. At the end of the third cycle, a further reduction in serum lipase $(270 \mathrm{U} / \mathrm{L})$, pancreatic isoamylase $(128 \mathrm{U} / \mathrm{L})$ and NSE levels $(21.6 \mu \mathrm{g} / \mathrm{L})$ was observed and was correlated with the radiological response of the tumor to therapy. The restaging CT scan showed a significant reduction in the number and size of both primary and metastatic lesions.

Given the patient's positive response to treatment and his good performance status, we decided to continue chemotherapy, obtaining a normalization of the serum lipase concentration (12 U/L vs. initial baseline level of $1343 \mathrm{U} / \mathrm{L})$ after the sixth cycle. In addition, total serum amylase dropped to $74 \mathrm{U} / \mathrm{L}$, NSE to $15.7 \mu \mathrm{g} / \mathrm{L}$ and CEA levels to $20.1 \mu \mathrm{g} / \mathrm{L}$ (Fig. 2). A second restaging CT scan of the chest and abdomen showed a further reduction in the size of the target lesions. However, a brain MRI revealed disease progression with multiple lesions and panencephalic brain radiotherapy was started. One month after the end of chemotherapy the patient was hospitalized due to the onset of epileptic seizures and progressive physical decline. Palliative care was begun but the patient died 1 week after admission ( 7 months after diagnosis).

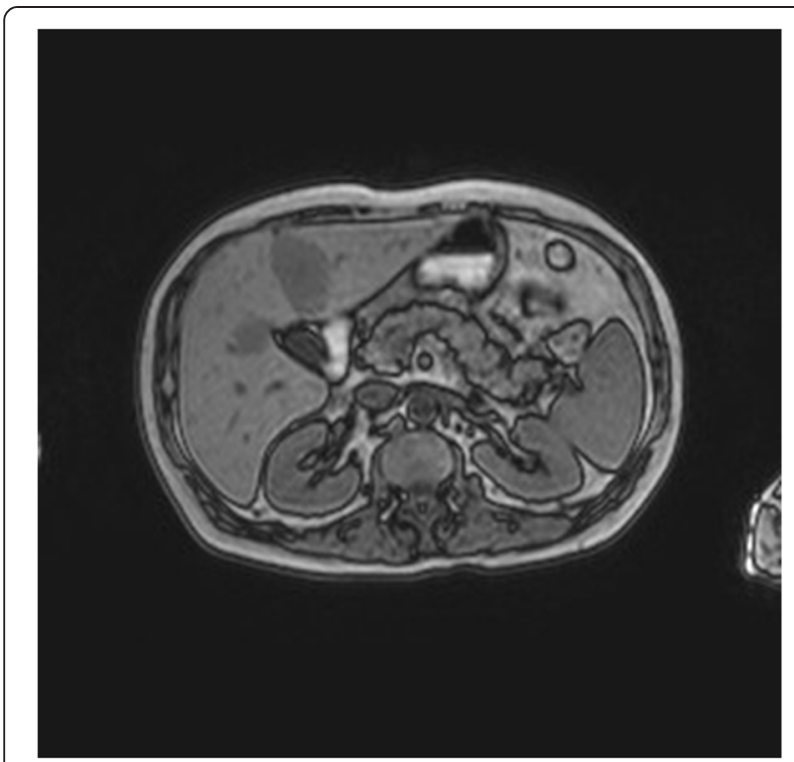

Fig. $1 \mathrm{MRI}$ was negative for acute pancreatitis and other diseases

\section{Conclusion}

SCLC is believed to arise from Kulchitsky cells which originate in the neural crest and are present beneath the epithelial lining of the lungs. It is also reported to have antigenic markers of both the neural crest and epithelium and to secrete polypeptide hormones and enzymes [1]. Cushing's disease, which is related to ectopic adrenocorticotropic hormone secretion, and the syndrome of inappropriate antidiuretic hormone secretion are the most frequent paraneoplastic endocrine complications in SCLC. There is anecdotal evidence of a correlation between lung cancer and marked hyperamylasemia. In fact, amylase-producing tumors of the lung include adenocarcinoma and undifferentiated small-cell carcinoma [2].

A review of the literature revealed only one case of metastatic SCLC with elevated paraneoplastic lipase production which was associated with SIADH, a second paraneoplastic condition [3, 4]. Our patient showed both lipase and pancreatic isoamylase elevation in the absence of acute pancreatitis or other non cancerrelated disorders.

Pancreatic amylase and lipase activity have been found in some human non-pancreatic organs such as the salivary glands, stomach, duodenum, large pancreatic ducts, extra-hepatic bile ducts and gallbladder. Elevation of amylase and lipase is seen in nonmalignant disorders such as acute pancreatitis, trauma, pancreatic abscess, cholecystitis, common bile duct obstruction, cholangitis and perforation or intestinal obstruction. A rare case of nonmalignant pancreatic hyperenzymemia was also reported by Gullo [4]. The syndrome, named after the researcher (Gullo's syndrome), is characterized by a fluctuating increase in pancreatic enzyme serum levels in the absence of pancreatic diseases.

In pathologic tissue, immunoreactivity for one or more pancreatic enzymes is found in the epithelial cells of salivary gland pleomorphic adenoma, squamous cell carcinoma of the esophagus, adenocarcinoma of pancreatic and biliary origin, and colorectal and gastric adenoma and adenocarcinoma. Terada et al. suggested that some tumors continue to express these enzymes after neoplastic transformation $[5,6]$. Isolated reports of hyperamylasemia in lung cancer would appear to be due to an increase in a salivary-like amylase isoenzyme [4].

As far as we know, this is the first report of a case of elevated lipase production associated with increased pancreatic isoamylase expression. There is strong evidence that both hyperlipasemia and pancreatic-type hyperamylasemia represent a paraneoplastic phenomenon. In our patient, diagnostic tests and the absence of clinical symptoms excluded inflammatory conditions or pancreatic disorders. The rapid decrease in enzyme levels shortly after the start of chemotherapy appeared to be closely related to the reduction in size and number of primary 


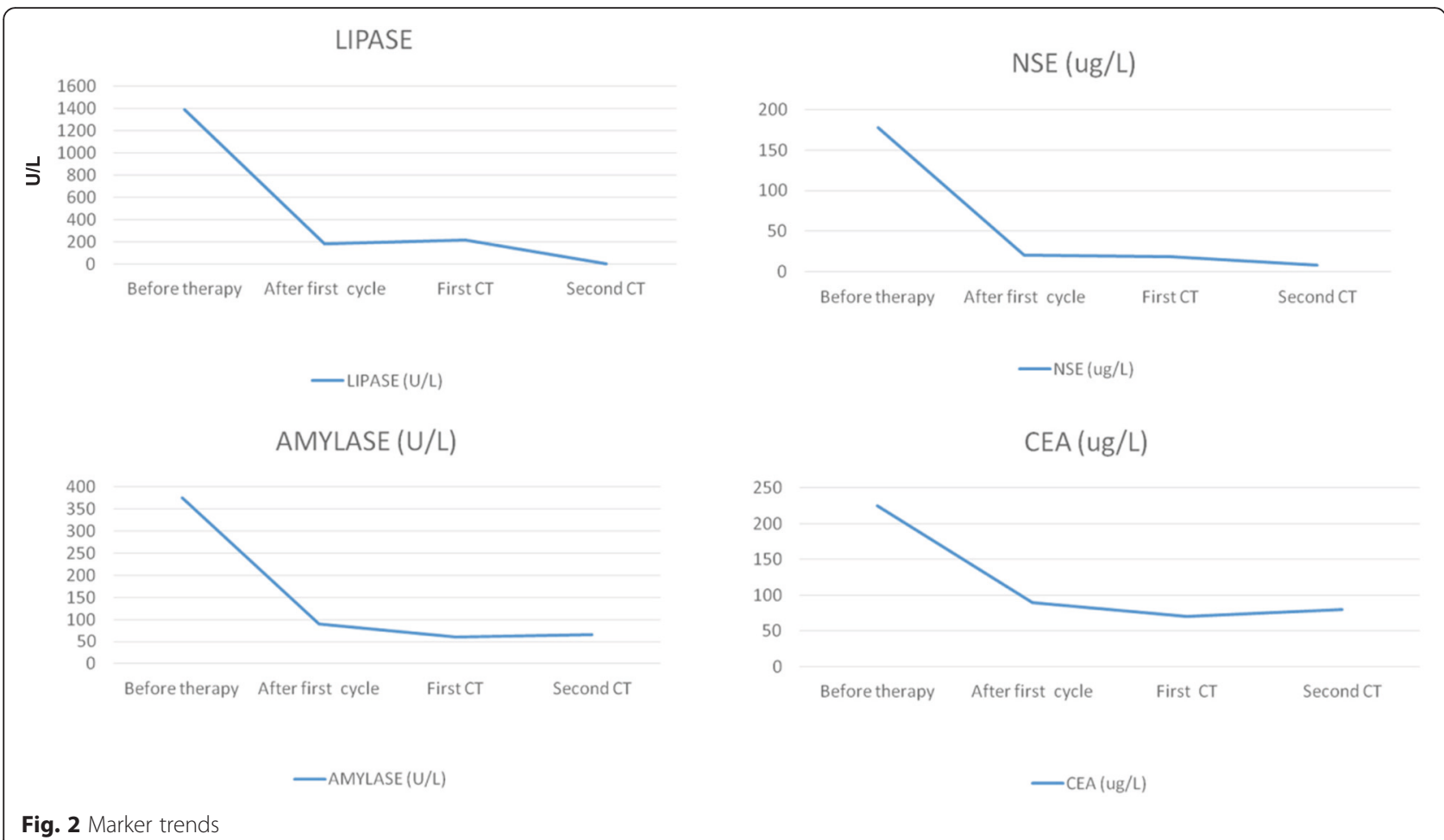

and metastatic lesions. Lipase and pancreatic isoamylase expression was confirmed by immunohistochemistry and the percentage of immunopositive tumor cells was evaluated with respect to the total number of tumor cells of the biopsy. Staining intensity was scored from 0 to $3+$. In particular, histological sections of the primary tumor showed $90 \%$ (intensity $1+/ 2+$ ) (Fig. 3a) and $100 \%$ (intensity 3+) (Fig. 3b) immunopositivity for amylase and lipase, respectively. Both enzymes showed marker-like behavior as their expression paralleled the response of the primary tumor to chemotherapy.

In conclusion, this is a very rare case of paraneoplastic syndrome linked to metastatic SCLC. The enzymes secreted could be considered for use as markers of response to treatment until clonal selection mechanisms and intratumor heterogeneity induce changes in biochemical characteristics and consequently in tumor behavior.

\section{Consent}

Written informed consent for publication of their clinical details and clinical images was obtained from the patient relative of the patient. A copy of the consent form is available for review by the Editor of this journal.
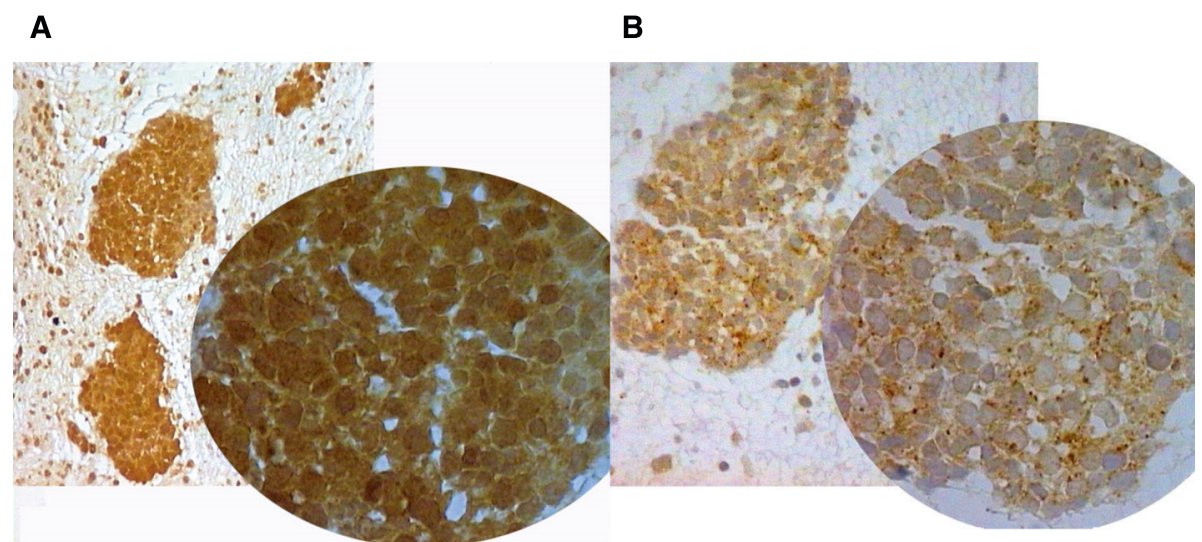

Fig. 3 Histological sections of the primary tumor showing $90 \%$ (intensity 1+/2+) (a) and $100 \%$ (intensity $3+$ ) (b) amylase and lipase immunopositivity 


\section{Abbreviations}

SCLC: small-cell lung cancer; SIADH: syndrome of inappropriate antidiuretic hormone secretion.

\section{Competing interests}

The authors declare that they have no competing interests.

\section{Authors' contributions}

ACG and MAB treated and observed the patient and performed the literature search. MM drafted the manuscript and performed the literature search. SB carried out the immunohistochemical tests. AD, AL, SP, MV, DA, GM and GLF revised the manuscript for important intellectual content. All authors read and approved the final manuscript.

\section{Acknowledgements}

The authors would like to thank Ursula Elbling for editing the manuscript.

\section{Author details}

'Department of Medical Oncology, Istituto Scientifico Romagnolo per lo Studio e la Cura dei Tumori (IRST) IRCCS, Meldola, Italy. ${ }^{2}$ Biosciences Laboratory, Istituto Scientifico Romagnolo per lo Studio e la Cura dei Tumori (IRST) IRCCS, Meldola, Italy.

Received: 16 April 2015 Accepted: 14 February 2016

Published online: 17 February 2016

\section{References}

1. Horai R, Nishihara H, Tateishi R, Matsuda M, Hattori S. Oat cell carcinoma of the lung simultaneously producing ACTH and serotonin. J Clin Endocrinol Metab. 1973;37:212-9.

2. Müssig $K$, Horger M, Häring HU, Wehrmann M. Syndrome of inappropriate antidiuretic hormone secretion and ectopic ACTH production in small cell lung carcinoma. Lung Cancer. 2007:57:120-2.

3. Benedetti G, Rasetlli F, Damiani S, Calandri C, Crinò L. Challenging problems in malignancy: case I. Presentation of small cell lung cancer with marked hyperamylasemia. J Clin Oncol. 2004;22:3826-8.

4. Gullo L. Chronic nonpathological hyperamylasemia of pancreatic origin Gastroenterology. 1996;1 10:1905-8.

5. Dasanu CA, Clark 3rd BA, Lahiri B, Ichim TE, Alexandrescu DT. Small cell lung cancer with paraneoplastic lipase production. South Med J. 2010;103:819-22. doi:10.1097/SMJ.0b013e3181e6369e.

6. Terada T, Kitamura Y, Ashida K, Matsunaga Y, Kato M, Harada K, et al. Expression of pancreatic digestive enzymes in normal and pathologic epithelial cells of the human gastrointestinal system. Virchows Arch. 1997: 431:195-203.

\section{Submit your next manuscript to BioMed Central and we will help you at every step:}

- We accept pre-submission inquiries

- Our selector tool helps you to find the most relevant journal

- We provide round the clock customer support

- Convenient online submission

- Thorough peer review

- Inclusion in PubMed and all major indexing services

- Maximum visibility for your research

Submit your manuscript at www.biomedcentral.com/submit 